\title{
An explanation of
}

workplace-based assessments in postgraduate dental training and a review of the current literature

- Explains the purpose and importance of workplace-based assessments (WBAs) in postgraduate training.

- Reviews the strengths and weaknesses of current WBAs used in postgraduate training.

- Stresses the importance of regular assessments to maximise the benefits of WBAs.

\author{
H. K. Kalsi, ${ }^{* 1}$ J. S. Kalsi ${ }^{2}$ and N. L. Fisher ${ }^{3}$
}

Workplace-based assessments (WBAs) are trainee-led formative assessments that measure the highest level of competence of the ability to do a task. So far WBAs are the only available assessment tools to measure performance integrated into practice. Over the years, WBAs have become an integral part of dental foundation and specialty training. The numerous WBAs available can be broadly categorised into three types. The first type involves observation of clinical encounters, for example mini-clinical evaluation exercises; direct observation of procedural skills; and dental evaluation of performance and procedure-based assessments. The second type involves discussion of clinical cases, such as case-based discussions. Finally, the third type includes the mini-peer assessment tool, team assessment of behaviour, $360^{\circ}$ assessments and multisource feedback, and all involve receiving feedback from a combination of colleagues, staff and patients. This article describes the WBAs currently used in postgraduate dental training and explores their strengths, weaknesses, perceived value by trainees and trainers and how these tools can be used in a reliable and valid way.

\section{INTRODUCTION}

Workplace-based assessment has been defined as the 'assessment of day-to-day practices undertaken in the working environment.' ${ }^{1}$ While there has always been a variety of methods used to assess knowledge and competence, workplace-based assessments (WBAs) are designed to assess a clinician's performance on a day-to-day basis in real life working conditions.

Miller's pyramid of competence demonstrates the various stages of knowledge and skills acquisition (Fig. 1) and shows how different assessment methods can assess the various levels of the pyramid. The need to assess performance at the highest level of Miller's pyramid, ('does'), has been highlighted by the observation that clinicians' performance in controlled assessment situations, for example objective structured clinical examinations (OSCEs), correlates

\footnotetext{
Postgraduate Student in MSc Conservative Dentistry, UCL Eastman Dental Institute, London; ${ }^{2}$ Specialty Registrar in Restorative Dentistry, Eastman Dental Hospital, UCLH NHS Foundation Trust, London; ${ }^{3}$ Emeritus Consultant in Restorative Dentistry, Guy's and St Thomas Hospital NHS Foundation Trust *Correspondence to: Mrs Harpreet Kalsi Email: happyharps@hotmail.com
}

\section{Refereed Paper}

Accepted 16 July 2013

DOI: 10.1038/sj.bdj.2013.1098

${ }^{\circledR}$ British Dental Journal 2013; 215: 519-524

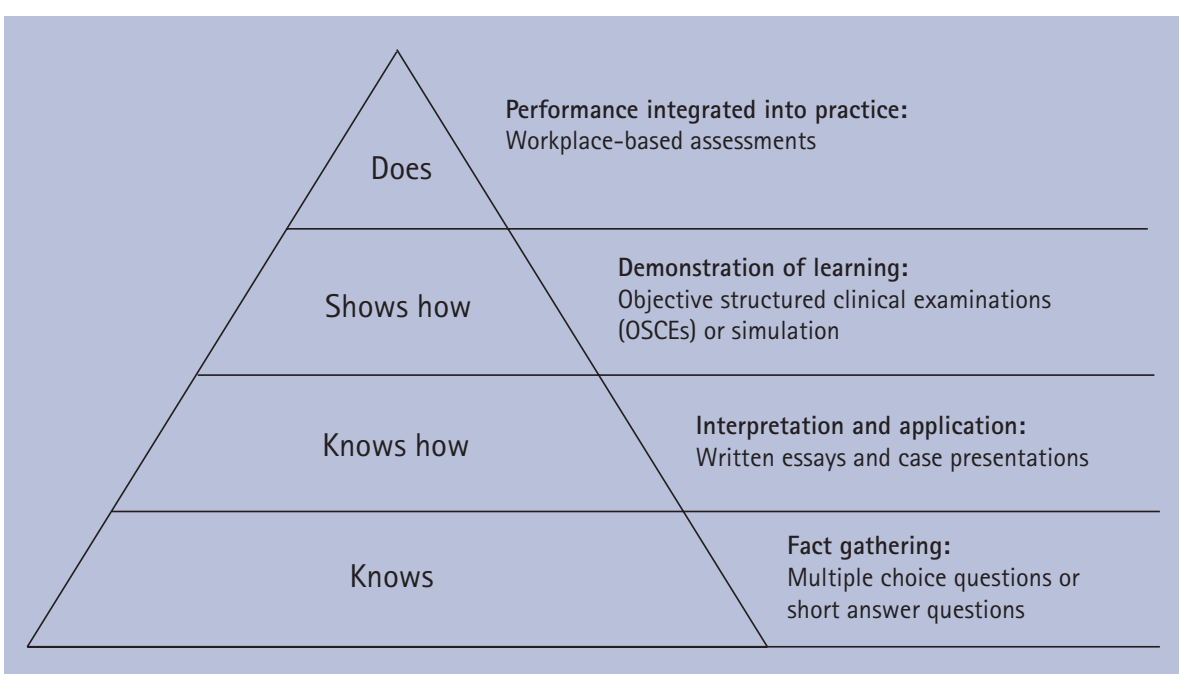

Fig. 1 Miller's pyramid of competence and how different methods of assessment can be used to assess the different levels

poorly with their professional performance in the workplace. ${ }^{2}$ For this reason, and the validity of the 'workplace' setting, WBAs have become a popular paradigm with an increasing number of assessment 'tools' and better understanding of their strengths and weaknesses.

Postgraduate dentistry has followed medicine with the introduction of WBAs into various training grades. The first to incorporate WBAs into a curriculum, under the auspices of the Committee of Postgraduate Dental Deans and Directors (COPDEND), was dental foundation training. In the past three years the dental specialties have followed suit with the mapping of WBAs to the domains listed in the new General Dental Council (GDC) approved curricula for specialty training. ${ }^{3}$ The aim of education and training within a dental foundation training programme is to produce a "competent, caring, reflective practitioner, able to develop their career in any branch of dentistry to the benefit of patients. ${ }^{4}$

A trainee in the context of this article is any individual who is currently in an 
educationally approved post. A trainer or evaluator is any individual who is involved in the training of another individual in an educationally approved post. The purpose of this article is to describe the use of WBAs currently available in dental postgraduate training and to explore their perceived value by trainees and trainers.

\section{DEVELOPMENT OF ASSESSMENT TOOLS}

Evaluation of clinical competence has evolved over the last 50 years. ${ }^{5}$ It became apparent during the 1950s that assessment of knowledge by written examination was insufficient and techniques more relevant to clinical practice emerged. Over the last 20 years performance-based assessment tools have been developed to more accurately evaluate clinical competence. ${ }^{6}$

The previous decade saw a move towards patient-centred training and a necessity for healthcare professionals to show their clinical competence and ability to work professionally with satisfactory communication and interpersonal skills. ${ }^{6}$ A drive to search for high quality tools that support training and evaluate competency of healthcare professionals ensued. The design of assessment tools that are robust, feasible and have educational value remains a challenge. ${ }^{6}$ Great progress, however, has been made with the development of a variety of traineeled WBAs that encourage self-reflection and the development of knowledge, understanding, skills and attitudes.

\section{TYPES OF ASSESSMENTS}

Summative assessments, for example, written examinations or OSCEs, grade trainees to determine their level of knowledge and, to some extent, skill. These assessments are used to provide information for decisions regarding achievement and progress. Summative assessment remains an integral and essential element in education conducted at, or after, the completion of training, and often in a setting far removed from the 'real world' of the workplace.

Formative assessments, for example WBAs, encourage a self-reflective process during learning and teaching, by providing trainees with feedback on their progress towards the acquisition of knowledge, understanding and skills, and their development of professional attitudes and insights. ${ }^{7}$ Demonstration of all-round

\begin{tabular}{|c|c|}
\hline $\begin{array}{l}\text { Clinical } \\
\text { 1. Patient examination \& diagnosis } \\
\text { 2. Treatment planing \& patient management } \\
\text { 3. Health promotion \& disease prevention } \\
\text { 4. Medical \& dental emergencies } \\
\text { 5. Anaesthesia, sedation, pain \& anxiety control } \\
\text { 6. Periodontal therapy \& management of soft tissue } \\
\text { 7. Hard \&t soft tissue surgery } \\
\text { 8. Non-surgical management of the hard \& soft } \\
\text { tissues of the head and neck } \\
\text { 9. Management of the developing dentition } \\
\text { 10. Restoration of teeth } \\
\text { 11. Replacement of teeth }\end{array}$ & $\begin{array}{l}\quad \text { Professionalism } \\
\text { 1. Ethics } \\
\text { 2. Professionalism with regard to patients } \\
\text { 3. Professionalism with regard to self } \\
\text { 4. Professionalism with regard to clinical team } \\
\text { \& peers }\end{array}$ \\
\hline $\begin{array}{l}\text { Communication } \\
\text { 1. Communication with the patient \& family } \\
\text { 2. Communication with the clinical team \& peers } \\
\text { 3. Communication with other professionals }\end{array}$ & $\begin{array}{l}\qquad \text { Leadership and management } \\
\text { 1. Personal \&t practice organisation } \\
\text { 2. Legislative } \\
\text { 3. Financial } \\
\text { 4. Leadership \& management }\end{array}$ \\
\hline
\end{tabular}

Fig. 2 Four domains of professional training and their major competencies

professional competence requires a combination of formative and summative assessment throughout the training period. This combination attempts to drive learning throughout training towards a standard of competence in all skill domains, ${ }^{6}$ and to ensure trainees are safe and independent on completion of training.

In recognition of the value of a patientcentred approach, the competencies for postgraduate dental training are now organised within four interlinked domains: clinical knowledge, communication, professionalism, leadership and management. Major competencies are defined within each domain (Fig. 2) and each major competency contains several specific supporting statements that describe the skills and attributes expected of a competent trainee to carry out a particular task. ${ }^{8}$ These skills and attributes are tested through the use of WBAs and achievement of a major competency requires the trainee to demonstrate competence in all the associated supporting competencies. To be deemed competent a trainee must be able to deal with complex professional tasks by combining the appropriate cognitive, psychomotor and affective skills. ${ }^{9}$ Both dental foundation and specialty trainees are assessed against the end point of their period of training.

\section{TYPES OF WORKPLACE-BASED ASSESSMENTS}

There are growing numbers of WBAs of increasing sophistication to assess different types of competencies within each of the four domains. Although the range of assessment methodologies can appear bewildering, the vast majority fall within one of three broad types. All WBAs are in essence 'observational', with variable amounts of dialogue. The first type, in which the majority of WBAs reside, rely normally on one evaluator, who is usually a trainer or supervisor, observing an aspect of professional practice and scoring and commenting appropriately. The second type involves discussion of clinical cases seen or treated by the trainee. The third type involves obtaining feedback, usually by means of questionnaires or surveys, from a variety of sources related to the workplace, such as support staff or patients.

Insight into one's performance with appropriate feedback and reflection can help the trainee and trainer evaluate the trainee's competence. Trainees' insight into their performance can also be assessed by trainers on WBA assessments ${ }^{7}$ (Tables 1 and 2), such as mini-clinical evaluation exercise (miniCEX) or direct observation of precedural skills (DOPs).

The following WBAs have been, or are being, used in dental foundation and specialty training.

\section{Observation of clinical encounters (Table 1)}

These WBAs involve an evaluator observing a trainee carrying out a clinical procedure.

Examples include the mini-CEX where the trainee undertakes a clinical activity such as taking a dental history or performing an oral examination. The trainee 
Table 1 Example of a dental evaluation of performance (A'DEP'T) record form

\begin{tabular}{|c|c|c|c|c|c|c|c|}
\hline \multirow[t]{2}{*}{$\begin{array}{l}\text { Please grade the following } \\
\text { areas using the scale } 1-6\end{array}$} & \multicolumn{2}{|c|}{$\begin{array}{l}\text { Needs improvement } \\
\text { before DFF* completion }\end{array}$} & \multirow{2}{*}{$\begin{array}{l}\begin{array}{l}\text { Borderline } \\
\text { for DFT } \\
\text { completion }\end{array} \\
3\end{array}$} & \multirow{2}{*}{$\begin{array}{l}\text { Acceptable } \\
\text { for DFT } \\
\text { completion } \\
4\end{array}$} & \multicolumn{2}{|c|}{$\begin{array}{l}\text { Above expectations for } \\
\text { DFT completion }\end{array}$} & \multirow[t]{2}{*}{ Not observed } \\
\hline & 1 & 2 & & & 5 & 6 & \\
\hline Patient examination & $\square$ & $\square$ & $\square$ & $\square$ & $\square$ & $\square$ & $\square$ \\
\hline Diagnosis/clinical judgement & $\square$ & $\square$ & $\square$ & $\square$ & $\square$ & $\square$ & $\square$ \\
\hline Treatment planning & $\square$ & $\square$ & $\square$ & $\square$ & $\square$ & $\square$ & $\square$ \\
\hline Procedural knowledge & $\square$ & $\square$ & $\square$ & $\square$ & $\square$ & $\square$ & $\square$ \\
\hline Technical ability & $\sqrt{2}$ & & & & & & - \\
\hline Communication (natient \& team) & $\square$ & $\square$ & $\square$ & $\square$ & $\square$ & $\square$ & $\square$ \\
\hline 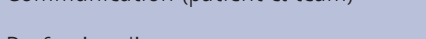 & $\square$ & $\square$ & $\square$ & $\square$ & $\square$ & $\square$ & $\square$ \\
\hline Professionalism & $\square$ & $\square$ & $\square$ & $\square$ & $\square$ & $\square$ & $\square$ \\
\hline Time management \& organisation & & & & & & & \\
\hline After feedback given on the assessment & $\square$ & $\square$ & $\square$ & $\square$ & $\square$ & $\square$ & $\square$ \\
\hline please rate: & $\square$ & $\square$ & $\square$ & $\square$ & $\square$ & $\square$ & $\square$ \\
\hline $\begin{array}{l}\text { Foundation dentist's insight into own } \\
\text { performance }\end{array}$ & $\square$ & $\square$ & $\square$ & $\square$ & $\square$ & $\square$ & $\square$ \\
\hline
\end{tabular}

*DF = Dental Foundation Training

Table 2 Example of case-based discussion (CbD) record form

\begin{tabular}{|c|c|c|c|c|c|c|c|}
\hline \multirow[t]{2}{*}{$\begin{array}{l}\text { Please grade the following } \\
\text { areas using the scale } 1-6\end{array}$} & \multicolumn{2}{|c|}{$\begin{array}{l}\text { Needs improvement } \\
\text { before DFT* completion }\end{array}$} & \multirow{2}{*}{$\begin{array}{l}\text { Borderline } \\
\text { for DFT } \\
\text { completion } \\
3\end{array}$} & \multirow{2}{*}{$\begin{array}{l}\text { Acceptable } \\
\text { for DFT } \\
\text { completion } \\
4\end{array}$} & \multicolumn{2}{|c|}{$\begin{array}{l}\text { Above expectations for } \\
\text { DFT completion }\end{array}$} & \multirow[t]{2}{*}{ Not observed } \\
\hline & 1 & 2 & & & 5 & 6 & \\
\hline 1. Patient recordkeeping & $\square$ & $\square$ & $\square$ & $\square$ & $\square$ & $\square$ & $\square$ \\
\hline 2. Investigations/referrals & $\square$ & $\square$ & $\square$ & $\square$ & $\square$ & $\square$ & $\square$ \\
\hline 3. Clinical diagnosis & $\square$ & $\square$ & $\square$ & $\square$ & $\square$ & $\square$ & $\square$ \\
\hline 4. Treatment planning & $\square$ & $\square$ & $\square$ & $\square$ & $\square$ & $\square$ & $\square$ \\
\hline 5. Follow up \& patient management & $\square$ & $\square$ & $\square$ & $\square$ & $\square$ & $\square$ & $\square$ \\
\hline 6. Professionalism & $\square$ & $\square$ & $\square$ & $\square$ & $\square$ & $\square$ & $\square$ \\
\hline 7. Overall clinical judgement & $\square$ & $\square$ & $\square$ & $\square$ & $\square$ & $\square$ & $\square$ \\
\hline 8. Case presentation skills & $\square$ & $\square$ & $\square$ & $\square$ & $\square$ & $\square$ & $\square$ \\
\hline $\begin{array}{l}\text { After feedback given on the assessment } \\
\text { please rate: }\end{array}$ & $\square$ & $\square$ & $\square$ & $\square$ & $\square$ & $\square$ & $\square$ \\
\hline $\begin{array}{l}\text { Foundation dentist's insight into own } \\
\text { performance }\end{array}$ & $\square$ & $\square$ & $\square$ & $\square$ & $\square$ & $\square$ & $\square$ \\
\hline
\end{tabular}

concludes the assessment with a summary of the key elements of the encounter, for example diagnoses, prognoses and management options. The evaluator then scores the trainee's performance against all the major competencies relevant to the procedure in each of the domains. Using this approach allows assessment or a wide range of attributes in a single assessment episode. ${ }^{10}$ DOPs are a variation of the mini-CEX designed specifically to assess and provide feedback on a trainee's ability to undertake a clinical procedure. Any element of the practice of dentistry is amenable to assessment using this tool and in many instances only one or two components of the clinical task are chosen to be assessed. For instance DOPs might be confined to the administration of a regional block local anaesthetic before a crown preparation. Being selective in this way has a number of advantages, such as reducing the amount of time needed for the encounter, targeting specific areas of previously identified clinical weaknesses and, where they exist, fulfilling curriculum requirements.
Due to their similarity in dental foundation training mini-CEX and DOPs have been combined to form a dental evaluation of performance test (A'DEP'T), ${ }^{4}$ specifically for dental foundation trainees. In specialty training a greater emphasis is being placed on procedure-based assessments (PBAs) that test the range of competencies required to perform an interventional procedure in its entirety, ${ }^{11}$ for example carrying out a surgical procedure or placing and restoring an implant. Assessing many dental procedures from start to finish can involve a longitudinal assessment over 


\section{EDUCATION}

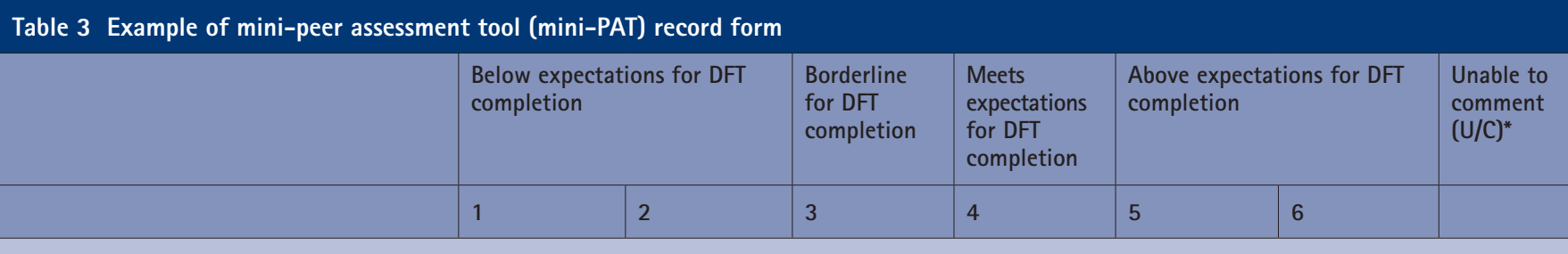

Good clinical care

\begin{tabular}{l|l|l|l|l|l|l}
\hline Ability to diagnose patient problems & & & & & \\
\hline $\begin{array}{l}2 \text { Ability to formulate appropriate } \\
\text { management plans }\end{array}$ & & & & & \\
\hline 3 Awareness of their own initiative & & & & & & \\
\hline $\begin{array}{l}4 \text { Ability to respond to psychosocial aspects } \\
\text { of illness }\end{array}$ & & & & & \\
\hline $\begin{array}{l}5 \text { Appropriate utilisation of resources for } \\
\text { example, ordering investigations }\end{array}$ & & & & & & \\
\hline
\end{tabular}

Maintaining good dental practice

6 Ability to manage time effectively/prioritise

7 Technical skills (appropriate current practice)

8 Willingness and effectiveness when

teaching / training colleagues

Relationship with patients

9 Communication with patients

10 Communication with carers and/or family

11 Respect for patients and their right to

confidentiality

Working with colleagues

\begin{tabular}{l|l|l|l|l|l|l}
\hline 12 Verbal communication with colleagues & & & & & & \\
\hline 13 Written communication with colleagues & & & & & & \\
\hline $\begin{array}{l}14 \text { Ability to recognise and value the } \\
\text { contribution of others }\end{array}$ & & & & & & \\
\hline 15 Accessibility/reliability & & & & & \\
\hline $\begin{array}{l}16 \text { Overall, how do you rate this dentist } \\
\text { compared to dentist ready to complete } \\
\text { dental foundation training }\end{array}$ & & & & & & \\
\hline
\end{tabular}

*U/C Please mark this if you have not observed the behaviour and therefore feel unable to comment.

Do you have any concerns about this dentist's probity or health?

If YES please state your concerns.

Anything especially good?

Yes $\square$ No

Please describe any behaviour that has raised concerns or should be a particular focus for development

an extended period of time. Each competency is rated according to the standard expected for the Certificate of Completion of Specialist Training (CCST).

\section{Discussion of clinical cases (Table 2)}

These are semi-structured discussions known as case-based discussions (CbDs) regarding the management of a patient treated or seen by the trainee, for example during a consultation clinic. The trainee is responsible for selecting the cases, but the trainee and evaluator should ensure that cases are well balanced and representative. The trainee usually presents at least two cases with the relevant patient records, radiographs and study casts, to the evaluator before the discussion is due to take place. The evaluator then selects one of these cases for discussion and judges the trainee's performance across several broad criteria such as clinical judgement, treatment planning and decision making skills. CbDs evaluate the trainee's understanding and rationale for the treatment provided. The evaluator should ensure that as many competencies are covered as possible for each case selected.

\section{Feedback of performance from clinical and non-clinical colleagues (Table 3)}

Examples include mini-peer Assessment 
tool (mini-PAT), team assessment of behaviour (TAB), $360^{\circ}$ assessments and multi-source feedback (MSF) from multiple assessors, each having a slightly different format. Assessment includes non-clinical aspects such as professionalism, communication and team-working skills. These WBAs also included the patient satisfaction questionnaire (PAQ).

Mini-PAT, TAB, $360^{\circ}$ assessments and MSF collect attitudes and opinions of colleagues on the trainee's clinical performance and professional behaviour. A combination of clinical and non-clinical colleagues who have observed the trainee in the workplace can be selected and should receive appropriate prior training on using these assessments. Completed forms should ideally be handed to someone other than the trainee, such as administration staff or the evaluator to keep the process anonymous. PAQ involves feedback from patients regarding the trainee's communication skills and professionalism. Again someone other than the trainee should hand out and collect the forms from a group of consecutive patients. A selected time should be reserved for the evaluator to go through the results of these assessments and provide the trainee with feedback.

\section{DISCUSSION}

The growing number of WBAs currently in circulation can be misunderstood by trainees and trainers, in particular how to use them in a reliable and valid way. Their strengths, weaknesses, perceived value by trainees and trainers have been explored to provide guidance to those embarking on the journey of using WBAs, whether in dental foundation or specialty training.

\section{Trainees and trainers views on WBAs}

Trainees find feedback from WBAs can provide support, increase confidence and highlight areas of weakness for development. ${ }^{12}$ Scoring is usually perceived as fair and an accurate representation of ability. ${ }^{12}$ However, assessments may be seen as time consuming with considerable paperwork, ${ }^{13}$ or as having an adverse impact on training. ${ }^{14}$

Trainers perceive WBAs to be clear, comprehensive, reflective and to highlight trainees with difficulties. ${ }^{12}$ The assessment process is seen as rewarding, but more so when the trainee performs well in dealing with a complex and challenging clinical situation. ${ }^{10}$

Table 4 Example of WBAs suggested for prosthodontic specialty training by the General Dental Council

Directly observed practical skills (DOPS)

Case-based discussion (CbD)

Mini clinical evaluation exercises (mini-CEX)

Multi-source feedback (MSF)

\section{Strengths of WBAs}

WBAs should promote feedback, encourage learning and improve performance but there is little evidence to show this to be the case. ${ }^{1}$ Feedback from trainers provides trainees with their strengths and weaknesses, ${ }^{15}$ aids personal development ${ }^{13}$ and allows trainees to reflect on their performance. ${ }^{16}$ Repeated use of WBAs, such as mini-CEX, increases trainees' confidence and can increase educational effects. ${ }^{15}$ Grieveson et al. ${ }^{12}$ concluded that feedback from WBAs may improve clinical practice and patient care.

Reflection is a skill involving mental processing that is applied to a complex or unstructured task where there is no obvious solution, ${ }^{17}$ which develops over time with practice. The tendency and ability to reflect varies between individuals and can depend upon the support of trainers. Unfortunately, there is no evidence to support or refute that reflection enhances competence. ${ }^{17}$ Trainee's insight into their performance can also be assessed through the use of WBAs and can be developed with experience and regular feedback. ${ }^{18}$

An increase in scores is expected over the trainee's year, in particular scores in clinical judgement, organisation and efficiency, ${ }^{10}$ and is consistent with the expected outcome of training. ${ }^{10}$ WBAs that observe clinical encounters, for example mini-CEX, are based on real settings and actual scenarios. ${ }^{15}$

\section{Weaknesses of WBAs}

Following feedback the willingness of trainees to change their behaviour is variable and can depend upon the manner with which the feedback is delivered and the support offered to effect change. ${ }^{1}$

Trainees may be anxious about achieving low scores at the beginning of the year and therefore delay their WBAs towards the end of the year. Davies et al. ${ }^{19}$ evaluated the first year of a foundation assessment programme and demonstrated that trainees submitted $40 \%$ of assessments in the last six weeks of their first year, also suggesting that the true value of the assessments was not fully appreciated. Trainees can become stressed and anxious when their clinical skills are being observed, especially during their first assessment. ${ }^{15}$

As WBAs are designed to be trainee-led and clinical scenarios are chosen by trainees, those trainees with difficulties may choose to avoid assessment of those clinical situations they find difficult and thus camouflage their incompetence. ${ }^{16}$ These individuals would benefit from having additional assessments throughout the year. ${ }^{19}$

Training and calibrating trainers before using WBAs is important to increase interrater reliability scoring and to differentiate between various performance levels. ${ }^{19-21}$ Trainers can usually distinguish between high- and low-performing trainees, but the varying types of questions and scales can be interpreted differently by individuals. ${ }^{21}$ Some trainers are also unwilling to score trainees on the lower end of the scale ${ }^{19,21}$ or give negative feedback. ${ }^{10}$ Trainers may also slightly overcompensate when scoring more challenging clinical situations. ${ }^{10}$ A recent national questionnaire study of 12 deaneries in England and Northern Ireland also confirmed that comprehensive training is required for both trainers and trainees using WBAs. ${ }^{22}$

\section{How to use WBAs}

Using individual WBAs in isolation is of limited value and different methods of assessment should be used to assess different levels of competence, based on Miller's pyramid (Fig. 1). ${ }^{9,23}$ Rather than using individual assessment methods, there has been a move towards using assessment programmes, as they combine several competence components and gather multiple sources of information, to gain an overall judgement of a trainee. ${ }^{9,19,24}$

Multiple WBAs facilitate validation of results by combining unique scenarios 
and multiple observers. The combination of several WBAs to assess competence of trainees, rather than relying on one assessment tool alone, enhances overall judgement of competence ${ }^{9,16}$ and increases reliability. ${ }^{9}$ Multiple and regular assessments with different assessors and clinical situations, ${ }^{10}$ and providing immediate feedback can increase reliability. ${ }^{9}$ Performance after each WBA should be recorded to give an overall picture of a trainee's competence. Quality assurance measures can prevent manipulation of WBAs, as well as set standards to identify and manage trainees with consistently unacceptable low performance. ${ }^{25}$

Monthly A'DEP'Ts and CbDs, and one PAQ and one MSF are currently required during dental foundation training. ${ }^{4}$ Feedback time can total to one hour per month per trainee, ${ }^{19}$ which seems feasible for the trainee, but may take up considerable trainers' time especially with a large number of assessments and trainees. One third of total time taken up with case-focused studies is from providing feedback. ${ }^{19}$ MSF and PAQ can reliably monitor workplace based performance ${ }^{25}$ but would require over 40 patients and at least six clinical and/or five non-clinical assessors to ensure reliability. This may be unfeasible in very small practices.

The GDC recommend various numbers of workplace-based assessments for specialty trainees per year. Table 4 shows the suggested number of WBAs to be carried out for prosthodontic speciality training. Online resources with details of GDC curricula and WBAs for use in dental specialty training exist, for example at https://www.iscp.ac.uk/, along with downloadable forms and guidance for use. Online portfolios to upload WBA results electronically exist for use in several UK deaneries for dental foundation training. This trend appears to be continuing in specialty training, although a cost may be incurred for speciality trainees to access online portfolios. Specialty specific WBAs are currently being developed, trialled and implemented by local training units and deaneries, with the potential of designing nationally accepted templates.

Outcomes such as learning, implementation of clinical skills and improved patient care have not been studied, ${ }^{20}$ and there is need for further research into formative performance assessment. ${ }^{1}$ Little available published dental literature exists regarding how to actually use WBAs, for example how to provide and increase the value of feedback, frequency, technique and how to spread out assessment over time, ${ }^{9}$ as well as why and when to use them and their associated problems. Unfortunately, the available evidence stems from medical retrospective or prospective observational studies and there are few studies using high levels of evidence.

WBAs and the understanding of their purpose and implementation has improved significantly over the past few years such that they are embedded in the philosophy of clinical training and education. Training of trainers has been highlighted as an important area to improve the understanding of outcomes.

In conclusion, more emphasis is being placed on ensuring a trainee is competent before embarking on their future career. WBAs are an essential tool that complements assessment methodologies such as examination to ensure that trainees develop the required proficiencies in a supervised environment. No other assessment tool reflects the competency to 'do' and this forms the underlying importance of WBAs. However, no research has reported the beneficial or negative outcomes of WBAs. Currently accepted regimes of WBA use appear to be empirical from a predominantly anecdotal evidencebase for setting frequency and numbers of use. Regular assessment with multiple assessors, unique scenarios at each assessment and providing immediate feedback can maximise the benefits of WBAs.

1. Miller A, Archer J. Impact of workplace based assessment on doctors' education and performance: a systematic review. BMJ 2010; 341: c5064

2. Rethans J J, Norcini J J, Baron-Maldonado M et al. The relationship between competence and performance: implications for assessing practice performance. Med Educ 2002 ; 36: 901-909.

3. Committee of Postgraduate Dental Deans and Directors. Dental gold guide 2011: a guide to postgraduate dental speciality training in the UK. Oxford: COPDEND, 2011.

4. Committee of Postgraduate Dental Deans. A curriculum for UK dental foundation programme training. (COPDEND). Regional Postgraduate Dental Education Office, 2006.

5. van der Vleuten $C P$, van Luijk S J, Schuwirth L W [Testing and development of tests in medical education]. Ned Tijdschr Geneeskd 1994; 138: 1288-1292 [In Dutch].
6. Prescott L E, Norcini J J, McKinlay P, Rennie J S. Facing the challenges of competency-based assessment of postgraduate dental training: Longitudinal Evaluation of Performance (LEP). Med Educ 2002; 36: 92-97.

7. Prescott-Clements $L E$, van der Vleuten $C P$, Schuwirth L, Gibb E, Hurst Y, Rennie J S. Measuring the development of insight by dental health professionals in training using workplace-based assessment. Eur J Dent Educ 2011; 15: 159-164.

8. Prescott LE, McKinlay P, Rennie J S. The development of an assessment system for dental vocational training and general professional training: a Scottish approach. Br Dent J 2001; 190: 41-44.

9. van der Vleuten C P M, Schuwirth LW T. Assessing professional competence: from methods to programmes. Med Educ 2005; 39: 309-317.

10. Norcini J J, Blank L L, Duffy F D, Fortna G S. The mini-CEX: a method for assessing clinical skills. Ann Intern Med 2003; 138: 476-481.

11. Marriott J, Purdie H, Crossley J, Beard J D. Evaluation of procedure-based assessment for assessing trainees' skills in the operating theatre. Br J Surg 2011; 98: 450-457.

12. Grieveson B, Kirton J A, Palmer N, Balmer M C. Evaluation of workplace based assessment tools in dental foundation training. Br Dent J 2011; 211: E8.

13. Wilkinson J R, Crossley J G, Wragg A, Mills $P$, Cowan $\mathrm{G}$, Wade W. Implementing workplace-based assessment across the medical specialties in the United Kingdom. Med Educ 2008; 42: 364-373.

14. Pereira E A, Dean B J. British surgeons' experiences of mandatory online workplace-based assessment. J Royal Soc Med 2009; 102: 287-293.

15. Malhotra S, Hatala $R$, Courneya C A. Internal medicine residents' perceptions of the Mini-Clinica Evaluation Exercise. Med Teach 2008; 30: 414-419.

16. Mitchell C, Bhat S, Herbert A, Baker P. Workplacebased assessments of junior doctors: do scores predict training difficulties? Med Educ 2011; 45: 1190-1198.

17. Mann K, Gordon J, MacLeod A. Reflection and reflective practice in health professions education: a systematic review. Adv Health Sci Educ Theory Pract 2009; 14: 595-621.

18. Prescott-Clements $L E$, van der Vleuten $C P$, Schuwirth L, Gibb E, Hurst Y, Rennie J S. Measuring the development of insight by dental health professionals in training using workplace-based assessment. Eur J Dent Educ 2011; 15: 159-164.

19. Davies H, Archer J, Southgate L, Norcini J. Initial evaluation of the first year of the Foundation Assessment Programme. Med Educ 2009; 43: 74-81.

20. Kogan J R, Holmboe E S, Hauer K E. Tools for direct observation and assessment of clinical skills of medical trainees: a systematic review. J Am Med Assoc 2009: 302: 1316-1326.

21. Crossley J, Johnson G, Booth J, Wade W. Good questions, good answers: construct alignment improves the performance of workplace-based assessment scales. Med Educ 2011; 45: 560-569.

22. Kirton J A, Palmer N O, Grieveson B, Balmer M C. A national evaluation of workplace-based assessment tools (WPBAs) in foundation dental training: a UK study. Effective and useful but do they provide an equitable training experience? Br Dent J 2013; 214: 305-309.

23. Mattheos N, Ucer C, Van de Velde T, Nattestad A. Assessment of knowledge and competencies related to implant dentistry in undergraduate and postgraduate university education. Eur J Dent Educ 2009; 13 (Suppl 1): 56-65.

24. Southgate L, Cox J, David T et al. The assessment of poorly performing doctors: the development of the assessment programmes for the General Medical Council's Performance Procedures. Med Educ 2001; 35 (Suppl 1): 2-8.

25. Murphy D J, Bruce D A, Mercer S W, Eva K W. The reliability of workplace-based assessment in postgraduate medical education and training: a national evaluation in general practice in the United Kingdom. Adv Health Sci Educ Theory Pract 2009; 14: 219-232. 